\title{
The Influence of Work Adjustment of Malaysian Expatriate Executives in Malaysian Construction Companies Overseas
}

\author{
H. Zainol ${ }^{1}$, A.M.A. Wahid ${ }^{2}$, A.C. Ahmad ${ }^{3}$, A.H.A.Tharim ${ }^{4}$, N. Ismail ${ }^{5}$ \\ 1,2,3,4,5 Faculty of Architecture, Planning and Surveying, Universiti Teknologi MARA (Perak), Perak, \\ Malaysia.
}

\begin{abstract}
The development of Malaysia's economy gives the opportunities for companies to explore and operate overseas. A company has to ensure that the selected individuals are willing to work abroad, have high perseverance and always ready to meet challenges. The success of implementing the overseas assignment does not solely depend on technical expertise. It also depends on non-technical issues such as the ability to interact with colleagues at work, adaptability to the new environment and openness to the local culture. Past studies found $65 \%$ of the companies indicated that $5 \%$ of their expatriates returned prematurely from their assignment. This research, however, proved that non-technical factor such as work adjustment ought to be considered by the company. One of the non-technical factors that contribute to the failure is the expatriate's inability to adapt to the new environment. This paper will also look into the factors that are faced by the expatriates during expatriation. The findings are obtained from empirical study and 64 respondents from Malaysian expatriate executives overseas. Suggestions and recommendations are given to improve the work adjustment of the expatriates.
\end{abstract}

\section{Introduction}

To achieve success, a company has to have a stable operation management and get full support from its personnel, especially the ones assigned to work in the respective countries. The company has to ensure that the selected individuals want to work abroad, have high perseverance and always ready to meet challenges. Such individuals could be moulded if the company has a well-organised development programme for expatriates, since the expatriates are the drivers that will determine the success of a multinational company abroad. The success in implementing overseas assignment does not solely depend on technical expertise; non-technical issues, including culture, family, work procedures, and ability to interact with colleagues at work, adaptability and openness to local culture also exert influence on the assignment. The involvement of expatriates in a host country does not only reflect the performance of the company that they represent, but also affects the contribution to the country they come from. The work adjustment during the assignment also influences the expatriates when working abroad. There are practices of expatriates as alluded to by Dessler, Griffiths [10]. The expatriate management in the global organization does not only emphasize the necessity of expertise for the success of an assignment.

Other aspects such as adaptation to the environment, family influence, the ability of communication with colleagues and being open to the local environment are the elements that are 
taken into account. According to Selmer [27], the more differences found in the environment of the host country, the longer length of time needed for adaptation. Those who cannot adapt will definitely be affected in their performance and, thus leads to failure in the implementation of the task area.

The purpose of this paper is to focus on work adjustment of the Malaysia executive expatriates in the host country. Past study has shown between 33\%-70\% difficulties in adjusting to new environment prompted the early return of expatriates to their country of origin as mentioned by Zainol, Tambi [35].

\section{Literature Review}

The involvement of expatriates in a host country does not only reflect the performance of the company they represent, but also affects the contribution to the country they come from. Work adjustment refers to a psychological comfort to assignment tasks or job. According to Chi and Chiou [8], work adjustment is the ability of the individual to understand and adapt to foreign cultures and to cope with the work environment.

The composition of employees in multinational companies is diversified. Local staff may make up the majority of the company's human resource to facilitate its management and operations Dessler, Griffiths [10], According to Minter [22], an expatriate might not know how to act and dress within a culturally diverse community of employees. Furthermore, he or she might have to make a lot of adjustments quickly to fit into an unfamiliar local work culture and environment and get on with his or her business assignment.

In their research, Harzing and Christensen [12] acknowledged that expatriate management was an extremely complex process that required a long term monitoring and implementation. The preassignment stage was the most critical stage of implementation where suitable expatriate managers were selected. Included in the pre-assignment stage was training needs analysis in person's context of expatriation and physical aspects. Some of the elements of work adjustment covered tasks in the new post, position at work, autonomy, work pressure, job satisfaction, promotion, using skill and knowledge and social standing as mentioned by Lee and Crocker [19], Selmer [28]. Although the international job description and specification had been determined by the home organisation, Selmer [28] stressed that the selection of suitable, well-trained candidates (if available) were of utmost importance for their performance carried the organisation's business reputation. The suitability of an expatriate in executing assignments in a host country was an important aspect that required a special emphasis.

Vance and Paik [33], Bonache [5] discovered an attractive salary, as a reward is an incentive for the executive expatriates to accept the assignment overseas. Job satisfaction will be affected if low salaries are received Past studies by Zhu, Luthans [36] revealed one of the reasons of expatriates to accept international assignments is because of the low salary received in the home country. According to Black, Gregersen [4] $77 \%$ of the expatriates were not satisfied with the compensation received during assignment. In multinational companies, satisfaction of salaries received will influence work performance. Low salary received, will result in job dissatisfaction and lead to migration to other companies.

Social standing is associated with the position and salary of the expatriates. The highest position in the organisation represents the standard of living of the person. According to Selmer \& Leung [29], social standing refers to living status, the post position in the organization and facilities given by the organisation. One of the main reasons of the individual to accept an international assignment is due to the high offers by the company without realizing the standard of living in the host country. Therefore, companies have to ensure all necessary steps taken to promote success and to overcome failure. Loss of social status and lifestyle changes can lead to negative impact on work adjustment.

Working with host nationals in an organisation relates to social adaptation of an individual. Different culture and work environment causes communication difficulty among expatriates and host nationals. A study done by Vance and Paik [33] showed that additional knowledge of the host 
country's culture was essential for expatriates to be effective when interacting with host nationals. Past literature discovered the acceptance expatriates by the host nationals in the organisation contributes to adaptation of work adjustment. When working abroad, the expatriates will be dealing with a variety of behaviours and different ways of working cultures. The strong integration between host nationals in multinational company is needed for adaptation in the new environment. The acceptance of home nationals working culture and practices facilitating the tasks performed. Eschbach, Parker [11] suggested the good working relationship among employees, understanding and effective communication encourage the organisation to grow.

Based on Pires, Stanton [25], the use of skills and technical competence encompasses knowledge, language and understanding of the assignment. This enables the expatriates to face any challenges. Black and Gregersen [3] believed the background of individual and experience contribute to the success of the expatriate assignment. These findings conflicted with Shay and Baack [32], where the success of expatriates adapting in the work environment in host country was based on skills and knowledge. The presence of expatriates is not only to bring in the expertise and skills to the host countries but also to gain and learn new experience through knowledge transfer, which is beneficial to the Malaysian construction companies overseas. Lee and Crocker [19] have confirmed those elements contribute to the success of the organisation and work adjustment of the expatriates. Individuals should act positively on the changes in the new environment to facilitate adjustment with host nationals.

\section{Methodology}

\subsection{Sample}

The sampling frame which was received from Malaysian Construction Industry Development Board, CIDB [7] indicated that 102 companies had ventured into projects overseas. Those companies were personally contacted. Only 60 companies had assigned their executive expatriates overseas. The questionnaires were sent together with a cover letter by email to the human resources manager for distribution to their construction company executive expatriates overseas. As proposed by Haslberger [13] this method is the best and effective way in getting responses from the expatriates. At present, distributing questionnaire using email is the most suitable method and get a high return rate as proposed by Babbie [2]. Haslberger [13] and Piaw [24] showed the snowball sampling method was used to obtain respondents. When the respondents replied, a letter of appreciation was sent to them.

The questionnaires were sent to the 349 respondents, via e-mail provided by the company, 'Qatar group', the Malaysian Club of Bahrain, and MAQSA (Malaysia Quantity Surveyor). Of the 349 questionnaires sent, 66 responses were received. Two respondents were not accepted because of nontarget groups. Thus, only 64 respondents were used. The total number of respondents is acceptable based on the study conducted by Causin and Ayoun [6] that received 66 expatriates and 46 respondents by Selmer \& Leung [30]. The return rate is $18.5 \%$ (64 questionnaires) and this is comparable with the study by Vidal, Sanz [34].

\subsection{Instrumentation}

The questionnaire covered three dimensions such as personal adjustment (13 variables), work adjustment (11 variables) and family adjustment (7 variables). There were 25 variables of expatriate dimensions. These dimensions and their measures were adapted from survey instruments based on previous findings. This paper concentrates on nine variables of work adjustment. The dimension consisted a number of measurement items that made use of a balanced five-point Likert scale, ranging from 1 (Completely Unadjusted) to 5 (Completely Adjusted) (Ascalon, Schleicher [1], Hoersting and Jenkins [15]. The variables obtained were tested by using factor analysis. Among the specific 
variables examined were tasks in the new post, pay, position at work, autonomy, work pressure/stress, work with host nationals, job satisfaction, promotion, skill in job and social standing.

\subsection{Factor Analysis and Reliabilities}

Factor analysis and reliability were used to answer the research question. According to Coakes, Steed [14], the purpose of using factor analysis procedure was to reduce the number of variables to a manageable group By reducing a data set from a group of interrelated variables, the maximum amount of common variance in a correlation could be achieved. The factors consisted of variables that were highly correlated among them. At least five variables required for factor analysis. A research review on exploration of 60 factor analysis found that the minimal sample size was 42 for factor analysis as suggested by Henson and Roberts [14]

Reliability analysis was used to find the value of the correlation between the score of each item. High correlation values showed have high reliability. The reliability of the value exceeding $\alpha<0.7$ was selected based on past studies by MacKenzie, Podsakoff [21]. In this study, 11 variables (items) were used for the expatriate adjustment and 64 sample size was considered adequate to meet the required variables for factor analysis.

\section{Findings and Discussion}

The purpose of the study is to identify the factors that influence the work adjustment of Malaysian expatriate executives while abroad. Based on previous studies, the variables are identified. Factor analysis was used to examine the loaded items for the correlated factors. For factor Analysis procedure, principle component analyses with varimax rotation were used. The procedure was successfully done and the items were reduced to nine. Analysis on work adjustment showed the variables were grouped into three factors namely, work environment, reward and task satisfaction (refer to Table 1). Working with local national and stress were dropped because the communalities value was less than 0.5 .

Table 1. Factor analysis of work adjustment

\begin{tabular}{lcl}
\hline Items & Factor Loading & Alpha \\
\hline Factor 1 Work Environment & & \\
Tasks in the new post & .790 & \\
Position at work & .736 & \\
Autonomy at work & .757 & .80 \\
Management Practices & .797 & \\
Factor 2 Reward & .882 & .78 \\
Pay & .858 & \\
Social Standing & .803 & \\
Factor 3 Task Satisfactions & .758 & \\
Job Satisfaction & .753 & .74 \\
Promotion &
\end{tabular}

Note: $\mathrm{N}=64$, Underlined loadings indicate the inclusion of that item in the factor ; $\mathrm{p}<.05^{*}, \mathrm{p}<.01^{* *}$

Kaiser-Meyer-Olkin=0.782, Barlett's Test Sphericity=197.52**, Anti-Image Correlation Matrix (range)=.71-.86, Total Variance Explained $=69.42 \%$. Cronbach's alpha coefficient of less than 0.7 were deleted.

The rotated factor loading results show the variables such as tasks in the new post, position at work, autonomy at work and management practices load highly on the first factor. These factors reflected the combination of work environment variables in this research. Items such as job 
satisfaction, promotion and using skill in present job load highly on the second factor that reflected the second factor. Items such as pay and social standing loaded highly in third factor. The first factor can be represented as work environment factor and the second factor can be grouped as reward. The third factor can be characterised as a task satisfaction reward. These three factors explain the variance of variables about $69.42 \%$ of the total sample variance. This shows a better factor solution for the variables. A Cronbach's alpha reliability was also tested for the newly named factors to ensure that items consist of factors that produce a reliable scale. The reliability scores obtained are: Work Environment $(\alpha=0.80)$, Reward $(\alpha=0.78)$ and Task Satisfaction $(\alpha=0.74)$. All the values are above 0.7 and this indicates the reliability of measurements.

By using principal component in the factor analysis, the items were reduced into three main factors that influence the Malaysian executive expatriates overseas. The results showed, the variables that fell under work environment were tasks in the new position, position at work, autonomy and management practices. The work environment and reward data have had a mean score depicted as 'adjusted' for all the four variables. Interestingly the task satisfaction was 'moderately adjusted' where the mean score is below 3.50 (refer to Table 2).

Table 2. Means and Standard Deviations of Work Adjustment

\begin{tabular}{lllll}
\hline Factor & \multirow{2}{*}{ Mean Factor } & Variables & Mean & SD \\
\hline Work Environment & \multirow{2}{*}{3.82} & Tasks in the new post & 4.12 & .63 \\
& & Position at work & 3.89 & .88 \\
& & Management Practices & 3.66 & .98 \\
& \multirow{3}{*}{3.51} & Autonomy at work & 3.61 & .92 \\
Reward & \multirow{2}{*}{3.47} & Pay & 3.53 & 1.01 \\
Task Satisfaction & Social Standing & 3.50 & 1.04 \\
& & Using skill in present job & 3.94 & 1.04 \\
& & Job Satisfaction & 3.50 & 1.04 \\
& & Promotion & 2.98 & 1.05 \\
\hline
\end{tabular}

Note: Mean of 1.0 to 1.49, not adjusted; 1.5-2.49, slightly adjusted; 2.5-3.49, moderately adjusted; 3.50-4.49, adjusted; 4.5-5.0, completely adjusted

\subsection{Work Environment}

As compared to reward and task satisfaction, work environment fell under 'moderately adjusted'. Task satisfaction was the most important element that influenced the work adjustment (mean=3. 82). Reward contributed the mean score 3.51, followed by task satisfaction which contributed the mean score 3.47. This variable shows the construction company selected suitable candidates for expatriate assignments. In addition, the executive expatriates that accepted the overseas assignments were those who were highly skilled and experience.

The most important element that influenced the work adjustment was task in the new post (mean= 4.12). Position at work (mean $=3.89$ ) was considered the second most important element in the work environment, reflecting on the expatriates' ability to socialize with the local people in the host country. Following the management practices of the host country (mean $=3.66$ ) came third, autonomy at work (mean $=3.61$ ) was fourth and the fifth item was pay (mean=3.61) All these variables can be considered as the main elements that influence the work adjustment of Malaysian executive expatriates overseas. All items showed respondents have no difficulties in the adaptation to work environment. The literature on expatriation also stresses the importance of adjustment when being in a different culture as mentioned by Kim and Slocum [17], Santoso and Martin [26]. The findings contradicted by previous studies, where such conditions do not apply to expatriate executives in the construction industry. They did not face any problems in the work environment. 


\subsection{Reward}

The second factor of work adjustment was reward for expatriates. Two variables correlated with each other on a matrix correlation. The variables were pay and social standing. The expatriate salary was the most important element in reward (mean=3.53). Social standing represented second most important (mean=3.50). All these variables are also depicted as 'moderately unadjusted'. Social standing can be considered as close to 'slightly adjusted'. Both aspects such as salary and social standing also described moderate satisfaction in term of reward. This suggests that consideration given by the company to the Malaysian executive is less. Such situation also led to dissatisfaction among Malaysian expatriate executives. According to Santoso and Martin [26] is the main factor that influences the development of intercultural competence. This will gear to a successful expatriate adjustment in the new culture.

\subsection{Task Satisfaction}

The output data show three variables correlated with task satisfaction. The variables used were skill in the present job, job satisfaction and promotion. The results showed the factor of task satisfaction with the mean score $<3.50$. Using skill in present job indicated the most important (mean=3.94) and job satisfaction was the second most (mean=2.50). Both items explained as 'moderately adjusted'. This data indirectly represent that the Malaysia expatriates were not satisfied when performing tasks. Though most of the expatriates sent by the companies were experienced but they were still 'slightly adjusted' with the work environment with host nationals. The last item in reward was promotion (slightly adjusted). The findings showed the expatriates have difficulties in promotion during assignment abroad. Many employees refuse to accept the international assignment demands because they fear of being left out for promotion Mezias and Scandura [20]. The results are parallel with the previous findings that showed that the element of promotion is the main thing that needs to be considered.

\section{Conclusions}

Preparation prior to departure is required to cope with the new environment in that never faced before. The election of expatriate executives does not only involve technical expertise, but also nontechnical aspects. Hence, the particular international companies have to get support from the workers, especially the professionals who are assigned to work overseas. The companies need to ensure that the chosen individuals are inclined to the overseas assignment and always ready to meet challenges. Such individuals can only be nurtured if the companies have well-organized expatriate development programmes, for the expatriates will be the prime mover who will ensure the success in the operations of the multinational companies abroad. When a worker is assigned to work in a host country, several things such as an incentive and psychological aspect need to be considered before the assignment. Although the assignment is temporary, its implication is big, such as moving family, children's education, different culture and environment. There are some constraints such as the respondent's rate. Due to the low number of responses received from the respondents, the possibility of potential biases of sampling exists in the study. Questionnaires were sent via email. The limitation occurs when the respondent did not receive the questionnaire due to invalid email address.

\section{References}

1. Ascalon, M. E., D.J. Schleicher and M.P. Born, 2008. Cross-cultural social intelligence. Cross Cultural Management, 15 (2): 109-130.

2. Babbie, E., 2010. The Practise of Social Research (12 ${ }^{\text {th }}$ ed.). CA: Wadsworth Cengage Learning. 
3. Black, J. S., and H.B. Gregersen, 2000. High impact training: Forging leaders for the global frontier. Human Resource Management, 39 (2,3): 173-184.

4. Black, J. S., H.B. Gregersen, H. B., and M.B. Mendenhall. 1992. Toward a theoretical framework of repatriation adjustment. Journal of International Business Studies, 23 (4): 737760.

5. Bonache, J, 2005. Job satisfaction among expatriates, repatriates and domestic employees: The perceived impact of international assignments on work-related variables. Personnel Review, 34 (1): 110-124.

6. Causin, G. F., and B. Ayoun, 2011. Packing for the trip: A model of competencies for successful expatriate hospitality assignment. International Journal of Hospitality Management, 30: 795802.

7. CIDB, 2009. Malaysian Contractors' Achievements in the Global Market, Construction Industry Development Board, Kuala Lumpur.

8. Chi, H.-K., and C.-Y. Chiou, 2007. The work adjustment of Taiwanese expatriates. The Business Review, 8 (2): 267-272.

9. Coakes, S. J., L. Steed, and P. Dzidic, 2006. SPSS version 13.0 for Windows Analysis Without Anguish. Sydney: John Wiley \& Sons Australia.

10. Dessler, Griffiths, and L. Walker, 2007. Human Resource Management - Theory, Skills, Application ( $3^{\text {rd }}$ ed.). New South Wales: Pearson Prentice Hall.

11. Eschbach, D. M., G.E. Parker and P.A. Stoeberl, 2001. American repatriate employees' retrospective assessments of the effects of cross-cultural training on their adaptation to international assignments. The International Journal of Human Resource Management, 12 (2): 270-287.

12. Harzing, A.W., and C. Christensen, 2004. Expatriate failure: Time to abandon the concept?. Career Development International, 4 (7): 616-626.

13. Haslberger, A., 2005. Facets and dimensions of cross-cultural adaptation: Refining the tools. Personnel Review, 34 (1), 85-109.

14. Henson, R. K., and J.K. Roberts, 2006. Use of exploratory analysis in published research. Education and Psychological Measurement, 66 (3): 393-416.

15. Hoersting, R. C., and S.R. Jenkins, 2011. No place to call home: Cultural homelessness, selfesteem and cross-cultural identities. International Journal of Intercultural Relations, 35: 17-30.

16. Hutchings, K., and S.W. Ratnasari, 2006. Cross-cultural non-work transition stresses: Domestic transferees in Indonesia. Cross Cultural Management: An International Journal, 13 (2): 114-131.

17. Kim, K., and J.W. Slocum. 2008. Individual differences and expatriate assignment effectiveness: The case of U.S.-based Korean expatriates. Journal of World Business, 43 (1): 109-126.

18. Lazarova, M., M. Westman and M.A. Shaffer, 2010. Elucidating the positive side of the workfamily interface on international assignments: A model of expatriate work and family performance. Academy of Management Review, 35 (1): 93-117.

19. Lee, L.-Y., and R. Crocker, 2006. A contingency model to promote the effectiveness of expatriate training. Industrial Management \& Data Systems, 106 (8): 1187-1205.

20. Mezias, J. M., and T.A. Scandura 2005. A needs-driven approach to expatriate adjustment and career development: A multiple mentoring perspective. Journal of International Business Studies, 36 (5): 519-538.

21. MacKenzie, S. B., P.M. Podsakoff and N.P. Podsakoff. 2011. Construct measurement and validation procedures in MIS and behavioural research: Integrating new and existing techniques. MIS Quarterly, 35 (2): 293-224.

22. Minter, R. L., 2008. Preparation of expatriates for global assignments: Revisited. Journal of Diversity Management, 3 (2): 37-42.

24. Piaw, C.Y., 2011. Kaedah dan Statistik Penyelidikan Kaedah Penyelidikan Buku 1. (2 ${ }^{\text {nd }}$ ed.). Kuala Lumpur: McGraw-Hill (Malaysia) Sdn. Bhd.

25. Pires, G., J. Stanton and S. Ostenfeld, 2006. Improving expatriate adjustments and effectiveness in ethnically diverse countries: Marketing insights. Cross Cultural Management: An International Journal, 13 (2): 156-170. 
26. Santoso. J and L. Martin, 2014. Expatriate management in Australian multinational enterprises. Construction Management and Economics, 31 (11): 1098-1109.

27. Selmer, J., 2006. Adjustment of business expatriates in Greater China: A strategic perspective. The International Journal of Human Resources Management, 17 (12): 1994-2008.

28. Selmer, J., 2007. Which is easier, adjusting to a similar or to a dissimilar culture. Cross Cultural Management, 7 (2): 185-201.

29. Selmer, J., and A.S.M Leung, 2003. Expatriate career intentions of women on foreign assignments and their adjustment. Journal of Managerial Psychology, 18 (3): 244-258.

30. Selmer, J., and A.S.M. Leung, 2007. Symptom and problem focused coping strategies of business women expatriates and their socio-cultural adjustment in Hong Kong. Women in Management Review, 22 (7): 588-605.

31. Shaffer, M. A., D.A. Harrison, H. Gregersen, J.S. Black, and L.A. Ferzandi, 2006. You can take it with you: Individual differences and expatriate effectiveness. Journal of Applied Psychology, 91 (1): 109-125.

32. Shay, J. P., and S. Baack, 2006. An empirical investigation of the relationships between modes and degree of expatriate adjustment and multiple measures of performance. International Journal of Cross Cultural Management, 6 (3): 275-294.

33. Vance, C. M., and Y. Paik, 2002. One size fits all in expatriate pre-departure training? Comparing the host country of Mexican, Indonesia and US workers. Journal of Management Development, 21 (7): 557-571.

34. Vidal, M. E. S., V.R. Sanz, M.I.B. Aragón, \& C. Brewster, 2007. Repatriation adjustment process of business employees: Evidence from Spanish workers. International Journal of Intercultural Relations, 31 ( 3): 317-337.

35. Zainol, H., A.M.A Tambi and A.R.A. Aziz, 2013. The preparedness of Malaysian multinational construction companies (MNCCs) in providing pre-departure and non-technical trainings for their expatriates, World Applied Sciences Journal, 25 (3): 391-398.

36. Zhu, W., F. Luthans, I.K.H. Chew, and C. Li, 2006. Potential expats in Singaporean organizations. Journal of Management Development, 25 (8): 763-776. 